\title{
Effect of Scroll Pin Profile and Tool Rotational Speed on Mechanical Properties of Submerged Friction Stir Processed AZ31B Magnesium Alloy
}

\author{
Sankar Ramaiyan ${ }^{a}$ Senthil Kumar Velukkudi Santhanam ${ }^{a}$, Puviyarasan Muthuguru $^{b}$ \\ ${ }^{a}$ Department of Mechanical Engineering, College of Engineering, Guindy - CEG, Anna University, \\ Chennai, 600025, India \\ ${ }^{b}$ Department of Mechanical Engineering, Panimalar Engineering College, Chennai, 600123, India
}

Received: August 27, 2017; Revised: December 20, 2017; Accepted: February 22, 2018

In this study, an effort has been made to choose an appropriate tool pin profile and rotational speed for a tool using a submerged friction stir processed hot rolled AZ31B magnesium alloy. A defect free process region was obtained using a novel tool shoulder, which consisted of a scroll. Three tool pin profiles, namely, simple cylindrical, stepped cylindrical and stepped square pin have been used. Tensile properties and fracture behavior revealed defect free friction stir processed specimens. The microstructural studies reveal the possibility of producing a defect free processed region using the stepped square pin tool geometry. The presence of fine recrystallized grains $(1.99 \mu \mathrm{m})$ and the absence of defects in the processed region lead to higher hardness and superior tensile properties.

Keywords: submerged friction stir processing, magnesium alloy, Tool Pin, Microstructure, Fracture.

\section{Introduction}

Magnesium $(\mathrm{Mg})$ alloys have been used in structural applications owing to their distinctive properties like high strength, good castability and low density. In some industries the use of magnesium alloy is very limited due to its poor workability and limited number of existing slip systems in the hexagonal close-packed structure ${ }^{1-3}$. Magnesium alloy has found application in structural components such as aerospace and automobile industries ${ }^{4-6}$ For example, magnesium parts are used in various vehicles in automotive industries such as Benze, Chrysler Jeep, Renault 18 Turbo and Ford light truck vehicles. The usage of magnesium alloy has reduced fuel consumption, due to the light weight of the engine ${ }^{7}$.

A variety of surface modification techniques have been used for improving the structural strength and grain refinement of various alloys, including, thermomechanical treatment $(\mathrm{TMT})^{8}$, high pressure torsion $(\mathrm{HPT})^{9}$, equal channel angular processing (ECAP) ${ }^{10}$, accumulative roll bonding $(\mathrm{ARB})^{11}$, friction stir processing (FSP) ${ }^{12}$, etc. Among the currently known processing techniques in industry, Friction Stir Processing (FSP) is an advanced process for changing the microstructure of the processed alloy ${ }^{13}$, which leads to the rearrangement of the structure and alter the grain size, which have been developed already through the use of the technique of Friction Stir Welding (FSW), introduced by TWI Ltd, United Kingdom in 1991. The FSW/FSP consists of a non-consumable tool with a shoulder and a pin which inserted into the workpiece for improvement in microstructure and mechanical properties of various alloys.
The stir zone (SZ) involves great microstructural changes, whereby a fine grain equiaxed microstructure is created by recrystallization ${ }^{14}$. As a result, FSP tool parameters play a vital role in obtaining superior mechanical properties. FSP parameters, namely, tool pin geometry, tool rotational speed and tool traverse speed are required for controlling the flow of material. Among these various parameters, the pin profile tool has an important role in the improvement in the material toughness or flexibility in the specific field of microstructure in magnesium alloys. Recently, a few researchers have indicated the possibility of using different tool pin designs which can make a significant improvement in hardness, grain refinement and microstructure changes of the FSP/FSW on magnesium alloy ${ }^{15-17}$ and aluminum alloy ${ }^{18}$.

The pin, or probe, and the shoulder are the main mechanisms. The main purpose of using the tool in the processing is to heat the workpiece due to friction, stirring deformed materials and moving the plasticized material under the tool shoulder and to produce the welded joint. The effect of square pin tool and cylindrical pin with threads tool pin geometries were considered in terms of the microstructure and mechanical strength of FSW joints of copper alloy and the test results revealed the presence on a finer recrystallized grain structure in the square pin tool and better mechanical properties compared to threaded cylindrical pin $^{19}$. Other studies have also confirmed the achievement of higher tensile strength by square pin and triangular pin compared to the welded sample using the cylindrical, taper and threaded tool pin profiles ${ }^{20}$. On the 
other hand, the scrolled shoulder tool has been found to be more effective than the conical pin for improving welding strength. However, both geometries require a optimum rotational speeds for avoiding internal defects. There was a greater grain refinement, higher hardness and improved strength in the stir zone using the scrolled tool geometry ${ }^{21}$.

Submerged friction stir processing (SFSP) is a new variance to FSP. The stirred zone of the SFSP sample presented fine and homogeneous grain growth when compared to FSP sample. It was due to limited recrystallization and grain growth seen in the magnesium alloy when cooled under water ${ }^{22}$. Fang Chai et $\mathrm{l}^{23}$ have conducted experiments on Submerged Friction Stir Processing (SFSP) of magnesium AZ91 light-weight alloy. They have noticed, FSP presenting a better material flow under submerged conditions than under the normal conditions (air). Rathinasuriyan et $\mathrm{al}^{24}$ have conducted submerged friction stir welding at different rotational speeds of 800,1000 and $1200 \mathrm{rpm}$ and water heads of 10 and $20 \mathrm{~mm}$, respectively, with the traverse speed and axial load maintained constant. A higher value of hardness was achieved from the submerged friction stir welded sample compared to the normal FSW sample due to higher cooling rate. Douglas et $\mathrm{al}^{25}$ did investigation on SFSP for magnesium alloy, where water was used as a medium in SFSP with production of better grain refinement than in air. Later authors ${ }^{26-27}$ have carried out experiments under a submerged condition. The results of such experiments indicate better results produced by submerged combination than from the conventional FSP/FSW. The mechanical and microstructure changes in the submerged welding/ processing have resulted in improved properties over the conventional FSW/FSP material. The above studies have established SFSP as one of the important processes for obtaining improvements in the mechanical properties and grain refinement of the materials. Limited research has also been carried out in SFSP of AZ31B magnesium alloy using various tool pin design resulting in getting the mechanical properties and microstructure refinement.

In this study, SFSP with of scrolled shoulder stepped tool pin profiles of several types (Scrolled CylindricalSCL, Scrolled Stepped Cylindrical-SSCL and Scrolled Stepped Square-SSSQ) have been used. The effect of the tool rotational speed has been studied and the resulting mechanical properties, microstructural and fracture behavior studies have been discussed.

\section{Materials and Methods}

Extruded AZ31B magnesium plates of $250 \mathrm{~mm}$ x 200 $\mathrm{mm} \times 6 \mathrm{~mm}$ thickness have been used in this investigation. Table 1 and Table 2 present the mechanical properties and elemental composition of AZ31B magnesium alloy used.
Table 1. AZ31B Mg composition (in weight \%).

\begin{tabular}{lcccccc}
\hline $\mathrm{Al}$ & $\mathrm{Mn}$ & $\mathrm{Si}$ & $\mathrm{Zn}$ & $\mathrm{Fe}$ & $\mathrm{Cu}$ & $\mathrm{Mg}$ \\
\hline 2.80 & 0.35 & 0.030 & 0.88 & 0.028 & 0.0020 & Balance \\
\hline
\end{tabular}

Table 2. Mechanical Properties of AZ31B Mg alloy.

\begin{tabular}{lcc}
\hline UTS & YS & \% Elongation \\
\hline $\mathrm{N} / \mathrm{mm}^{2}$ & $\mathrm{~N} / \mathrm{mm}^{2}$ & $\%$ \\
255 & 217 & 10 \\
\hline
\end{tabular}

A tool shoulder diameter of $24 \mathrm{~mm}$ with varying pin profiles, including a Scrolled Cylindrical (SCL), a Scrolled Stepped Cylindrical (SSCL) and a Scrolled Stepped Square (SSSQ) were fabricated using H13 tool steel. They had hardness of approximately $60 \mathrm{HRC}$. Based on the previous experimental work ${ }^{28}$, the shoulder diameter of $24 \mathrm{~mm}$ was used for getting a defect free process region. A scroll was introduced in the entire tool shoulder surface for facilitating microstructural changes. This reduced the tunneling defect in the processed workpiece ${ }^{26}$. This is a novel feature of the present investigation. The tools used for the preparation of the tool pins and fabricated pin profiles are presented in Fig. 1.

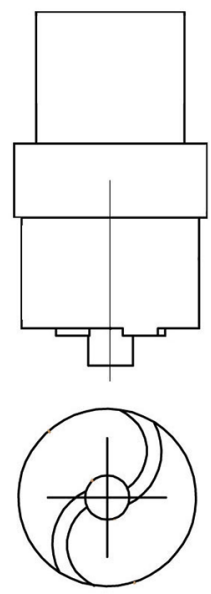

a) $\mathrm{SCL}$

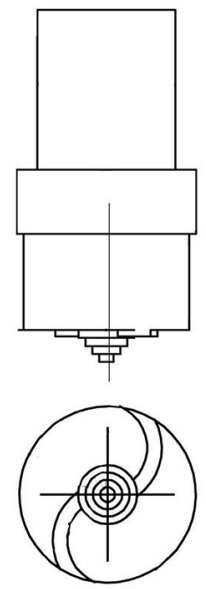

b) $\mathrm{SSCL}$
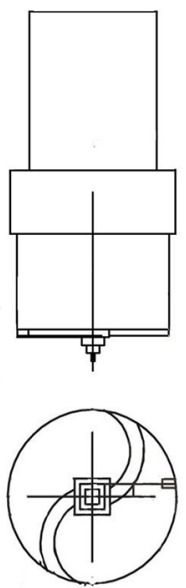

c) SSSQ
Figure 1. Different types of scroll shoulder, stepped tool pin profiles Scrolled Cylindrical (SCL), Scrolled Stepped Cylindrical (SSCL), and Scrolled Stepped Square (SSSQ)

The experiment was carried out in an indigenously made friction stir processing machine (servo controlled, Make: Creative Automations) under submerged condition. Water was used as a medium for submersion. The workpiece material is used for conducting the experiment, consisted of AZ31B magnesium plates. SFSP was conducted on the surface of AZ31B alloy sheets of $6 \mathrm{~mm}$ thickness. The FSP tool is mounted on the FSW/FSP machine (3 axis servo controlled) and the extruded AZ31B plates were placed using a specially fabricated fixture, which was kept inside an acrylic tank and fixed to the machine table. The experimental set-up and the firmly clamped workpiece are shown in Figs. 2 (a) and (b). 


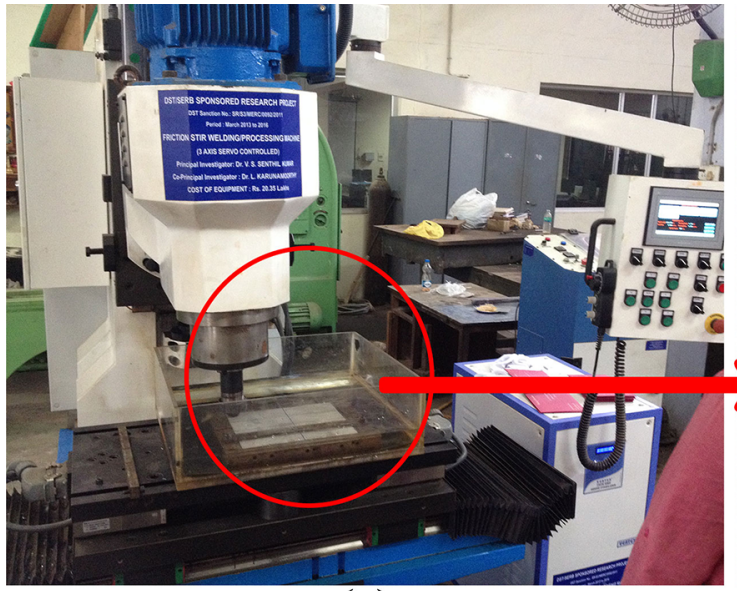

(a)

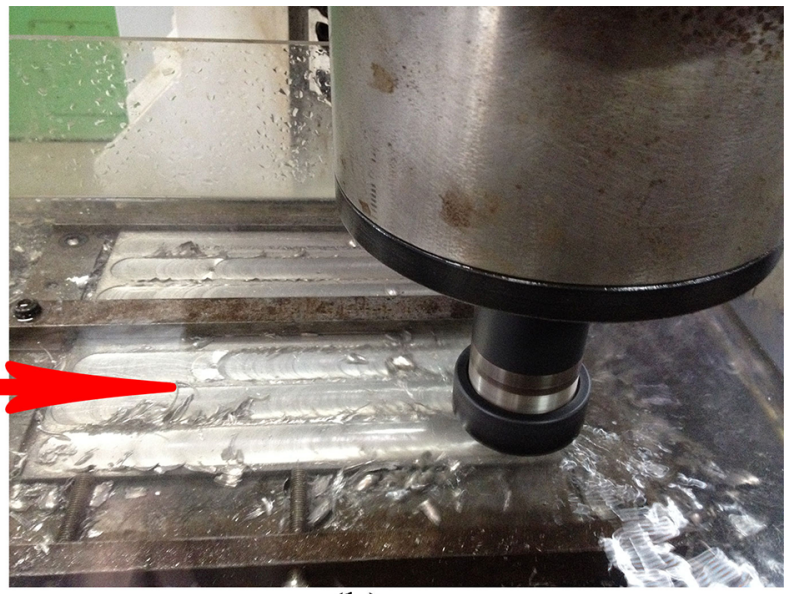

(b)

Figure 2. (a) Experimental Setup for FSP (b) Closer view of processing.

Three different tool rotational speeds and tool pin profiles have been considered for this study. All the processes were carried out for a single pass with a constant traverse speed of $60 \mathrm{~mm} / \mathrm{min}$, which produced superior mechanical properties. The levels were chosen on the basis of the findings seen in available literature and the availability of the machine. The responses considered for analyzing the submerged friction stir processed plates were Ultimate Tensile Strength (UTS), Microhardness $\left(\mathrm{HV}_{0.5}\right)$ and \% Elongation.
Tensile test was conducted using INSTRON of universal testing machine with a capacity of $50 \mathrm{KN}$. A standard tensile test specimen with $20 \mathrm{~mm}$ length and a width of $6 \mathrm{~mm}$ was cut using wire-cut EDM through the ASTM standard E 2448. The tensile specimen used for conducting experiments and the dimension of the specimen used are presented in Fig. 3.

Hardness of the specimen was measured using a Vickers hardness tester. The parameters, namely, \% elongation and UTS were measured using a computer interface. SFSP is

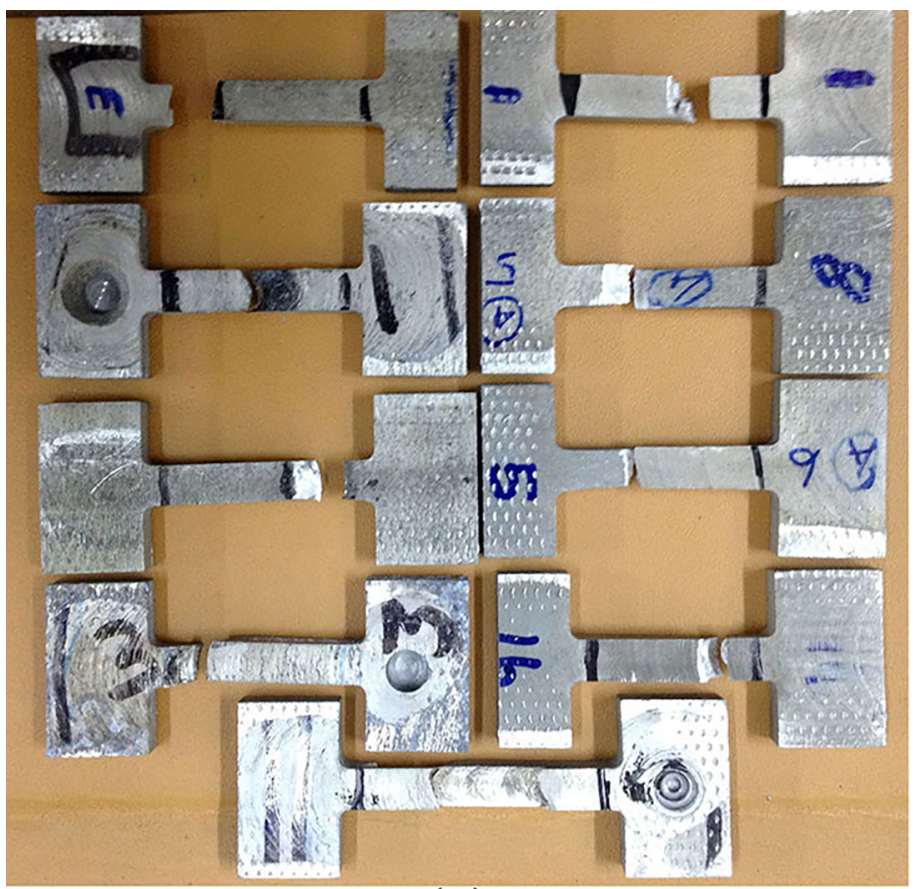

(a)

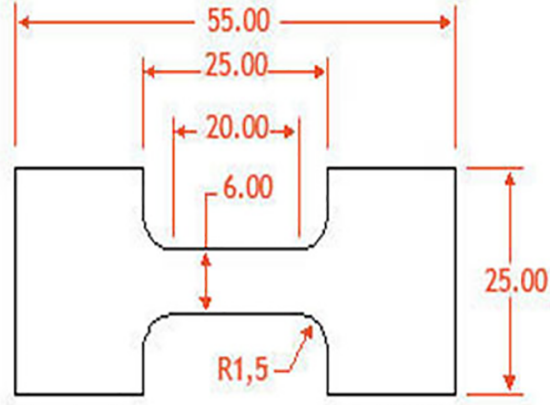

All dimensions are in mm (ASTM E2448)

Figure 3. Schematic illustration of (a) Tensile samples (b) Geometry of tensile test specimen 
an important process, currently used in industries for grains refined with improved properties.

\section{Results and Discussion}

\subsection{Evaluation of Mechanical properties}

The engineering stress- strain curves of the SFSP samples at various rotational speeds, tool pin profile with a constant traverse speed are shown in Figs. 4 (a-c).

Figs. 5(a-c) summarizes the tensile properties for all cases. Among the various samples, the sample was fabricated under the condition of tool rotational speed of $1000 \mathrm{rpm}$, tool pin profile of SSSQ, which has exhibited a higher ultimate strength of $245 \mathrm{MPa}$, elongation of $23.46 \%$ and micro-hardness of $112\left(\mathrm{HV}_{0.5}\right)$. This was possible due to the heat produced during the high speed of rotation at this particular traverse speed. Grain size was found to be small in the same condition. This played a major role in the determination of the tensile strength of the processed AZ31B magnesium alloy. The confinement time of the ploughed material in the shoulder profile had an effect on the softening of the ploughed material. The degree of softening and subsequent cooling determines recrystallization. The confinement time of the ploughed material in SSSQ tool was found to be more than for the other tools, since, the escape of ploughed material from the SSSQ tool cavity was difficult, when compared to concave shoulder tool concavity. This has favored considerable achievement in ductility with SSSQ pin profile, considering its leading to the fine grain size due to an unusual Hall-Petch effect ${ }^{29}$.

The error bars of the tensile strength, hardness and elongation were calculated using standard deviation method as shown in Fig. 6. The maximum error values of tensile strength, hardness and elongation were $7 \%, 5.93 \%$ and $7.21 \%$ respectively. These error values were within the acceptable limits. So that the experimental values of tensile strength, hardness and elongation in trial 1 are good agreement within trial 2 or trial 2 has good agreement with the experiment trial 1. SFSP is one of the important techniques used for improving the formability characteristics of AZ31B magnesium alloy. Processing the samples using different pin profile affects
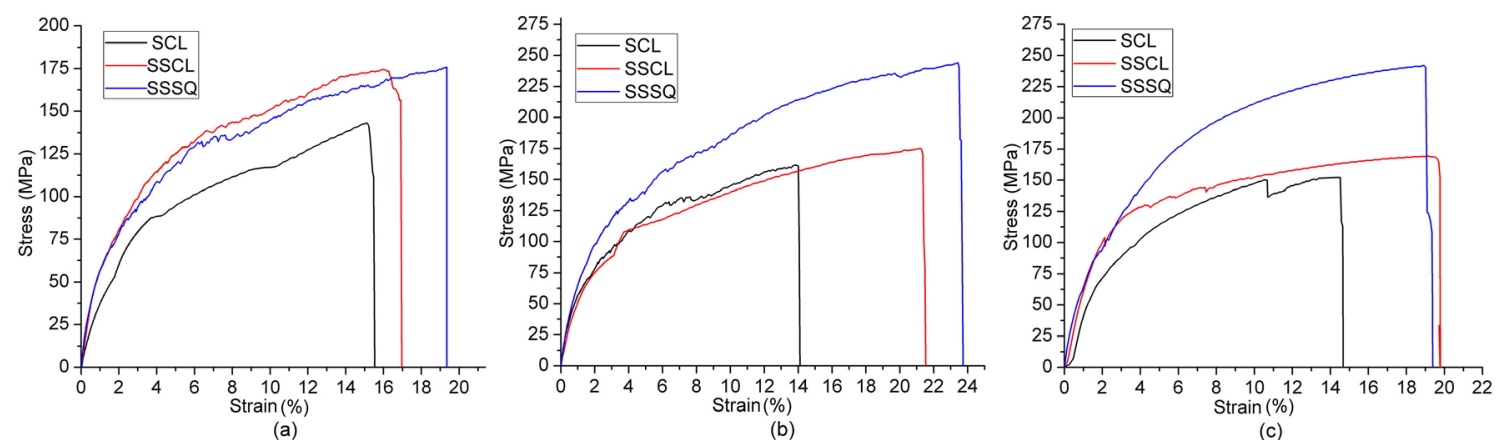

Figure 4. Stress- Strain curve in the SZ at (a) 800 rpm (b) 1000 rpm (c) 1200 rpm. Scrolled Cylindrical (SCL), Scrolled Stepped Cylindrical (SSCL), and Scrolled Stepped Square (SSSQ)
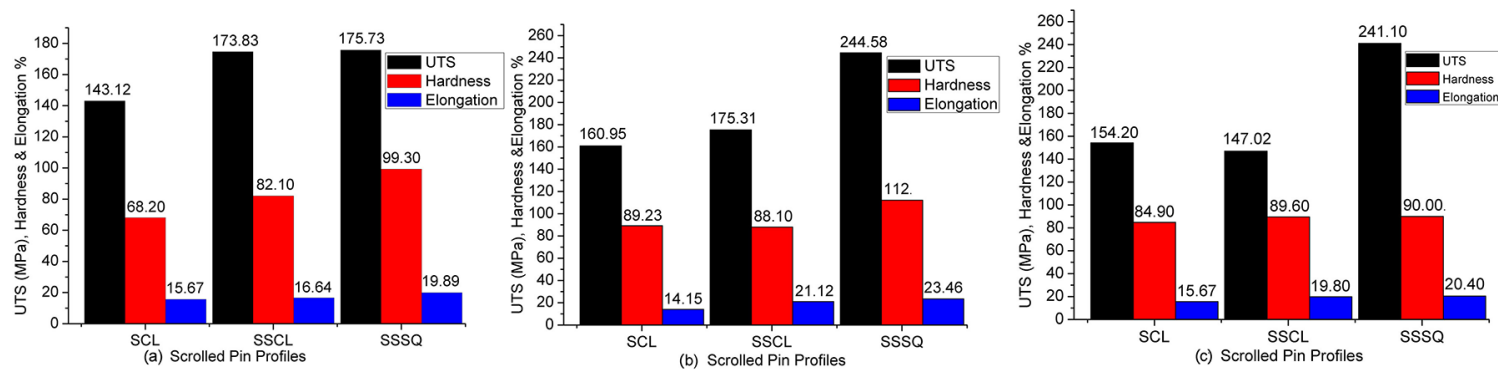

Figure 5. Mechanical properties of different scroll tool pin profiles at (a) $800 \mathrm{rpm}$ (b) $1000 \mathrm{rpm}$ (c) $1200 \mathrm{rpm}$
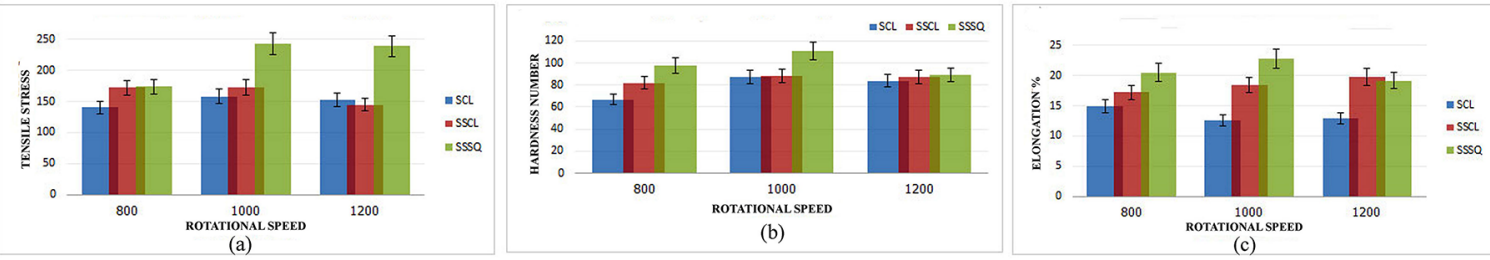

Figure 6. Error bar (a) Tesnile Stress (b) Hardness (c) Elongation 
their mechanical properties, since they are directly related to the thermal fields and the microstructure obtained thereof.

\subsection{Micro-hardness study}

The vicker's micro-hardness of the SFSP samples processed using different scrolled pin profiles was measured across the processed zone at the middle. The results are provided in Figs. 7 (a-c). The micro hardness of raw metal was seen as 72 $\left(\mathrm{HV}_{0.5}\right)$. The SSSQ pin geometry at $1000 \mathrm{rpm}$ exhibited higher hardness of $112\left(\mathrm{HV}_{0.5}\right)$ in the stir zone, which is compared with their counterparts. The reasons were: (1) Decrease in the size of the grain in the processed region during the use of SSSQ tool pin. This was also stated by (Amirafshar) that the FSP increases material dislocation density thereby the grain and sub-grain boundaries because the main obstacles to the slip of dislocations. Hence the materials with finer grain size would have higher hardness or strength as they impose additional restrictions on the dislocation movement ${ }^{30}$. (2) According to Orowan strengthening mechanism, the intermetallic particles also help in improving the hardness ${ }^{31}$.

The difference in hardness between the various samples due to the difference in grain change in the stirring zone. At a specific condition (1000 rpm, SSSQ pin profile), the tool provides optimum plastic deformation, which leads to more grain refinement. Further, increase in the rotational speed $(1200 \mathrm{rpm})$ increases the grain size and decreases the micro-hardness, which is supported by previous literature ${ }^{32}$.

\subsection{Macrostructural Studies}

Generally, FSP/FSW are free from these defects since there is no melting taking place during welding or processing and the metals are joined in the solid state itself considering the heat produced by the friction and flow of metal by the stirring action. However, FSW joints are prone to other defects like pinhole, tunnel defect, cracks, piping defect etc. due to inadequate flow of metal and insufficient consolidation of metal in the FSW region ${ }^{8}$. Hence, the processed samples in this examination were analyzed at low magnification (10) using an optical microscope for revealing the quality of SFSP region at a rotational speed of $1000 \mathrm{rpm}$ and traverse speed of $60 \mathrm{~mm} / \mathrm{min}$ and they are presented in Table 3. The figures do not show any voids or cracks on the surface and cross-section of the processed specimen. However, comparing Table 3 (a, $\mathrm{b}$ with $\mathrm{c}$ )), the SCL tool shows creation of excessive flash (shown by arrows), especially on the retreating side (RS), while the surface of the other two specimen exhibits a very smooth quality and particular rings without any prominence or depression Table 3(c).

\subsection{Microstructure Analysis}

The microstructure of AZ31B magnesium alloys was analyzed using an Optical Microscope (OM) and Scanning Electron Microscope (SEM) images. The microstructure of the base metal observed before the
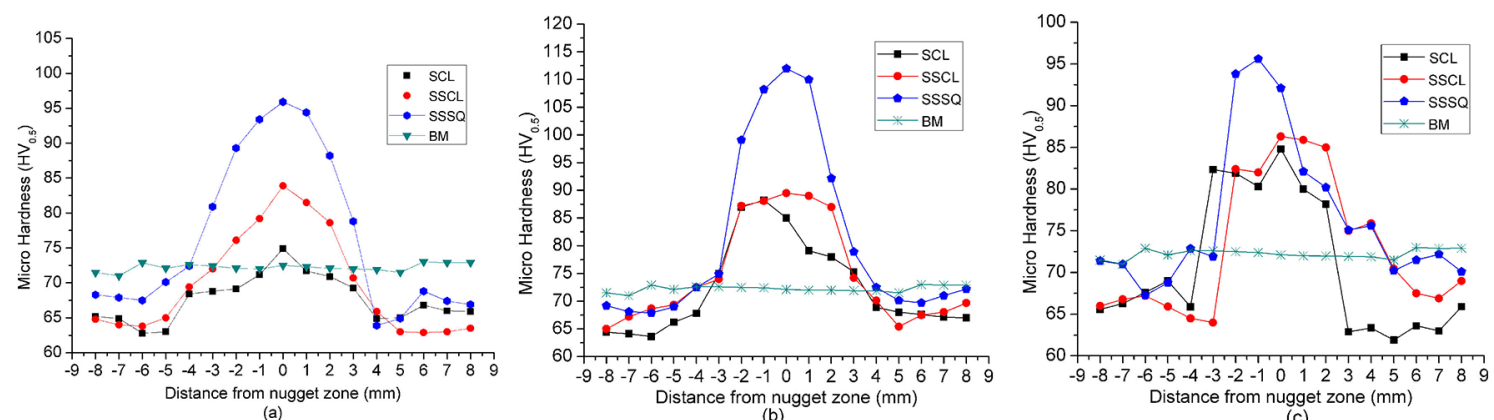

Figure 7. Micro-hardness various scroll pin profiles of the sample produced by SFSP at a) $800 \mathrm{rpm}$ b) $1000 \mathrm{rpm}$ c) $1200 \mathrm{rpm}$. Scrolled Cylindrical (SCL), Scrolled Stepped Cylindrical (SSCL), and Scrolled Stepped Square (SSSQ)

Table 3. Macrostructure and observations of processed region at $1000 \mathrm{rpm}$.

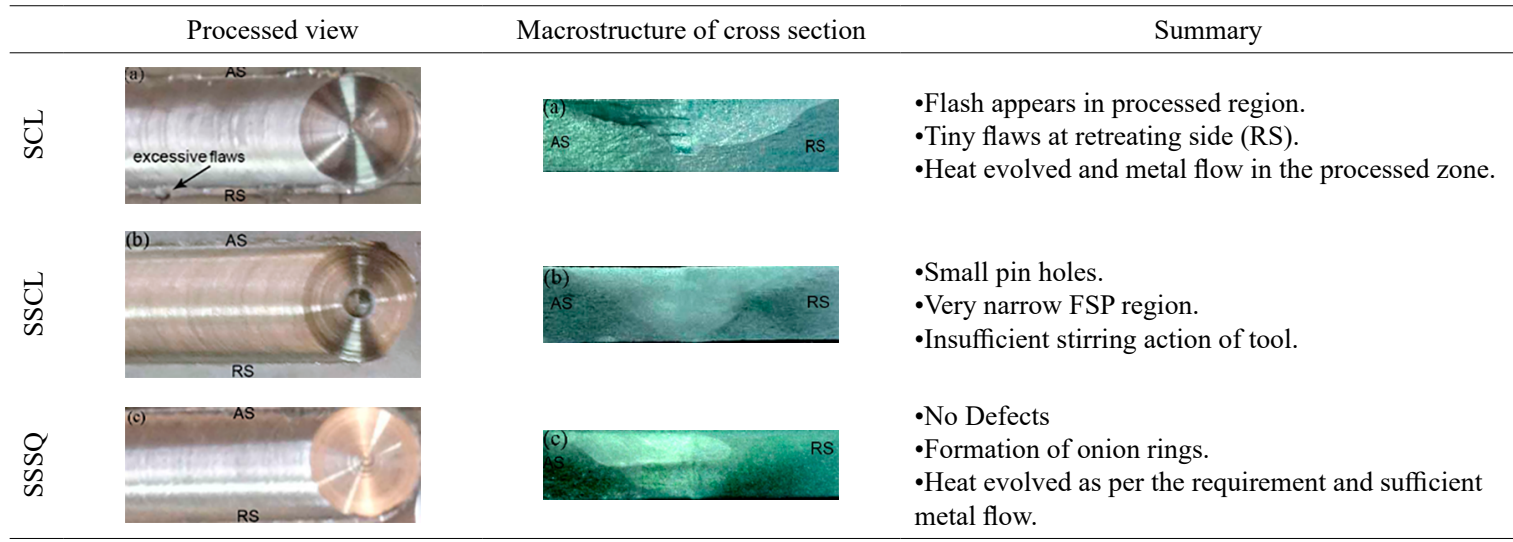


SFSP process is presented in Fig. 8(a). It shows the recrystallized grains of primary magnesium solid solution with particles of Mn-Al as dark phases. Fig. 8(b) shows the microstructure of the AZ31B magnesium alloy using SEM, which indicates the compounds of elongated coarse grains structure.
The effects of various forms of tool pin geometry in submerged conditions on the resulting microstructure at three different zones in the cross-section of AZ31B alloy with a1000 rpm rotational speed and traverse of $60 \mathrm{~mm} /$ min are presented in Fig. 9(a-i). Based on the observations, general defects such as voids and cracks are not observed

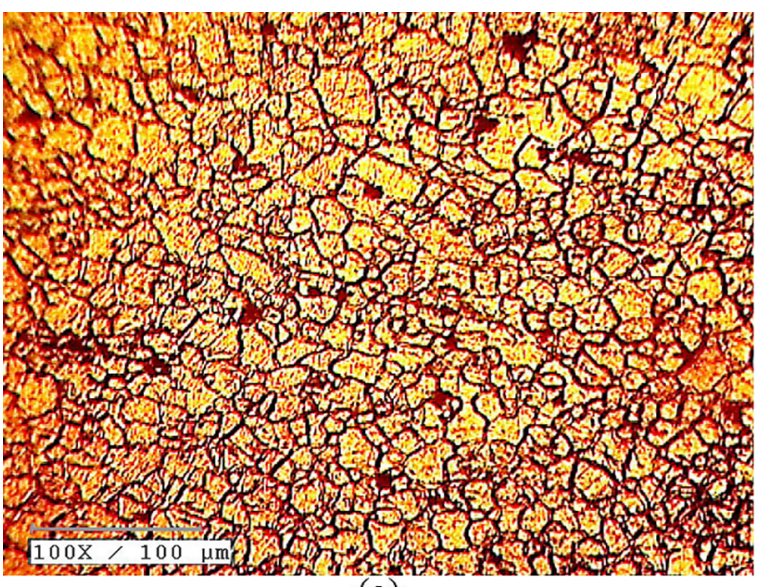

(a)

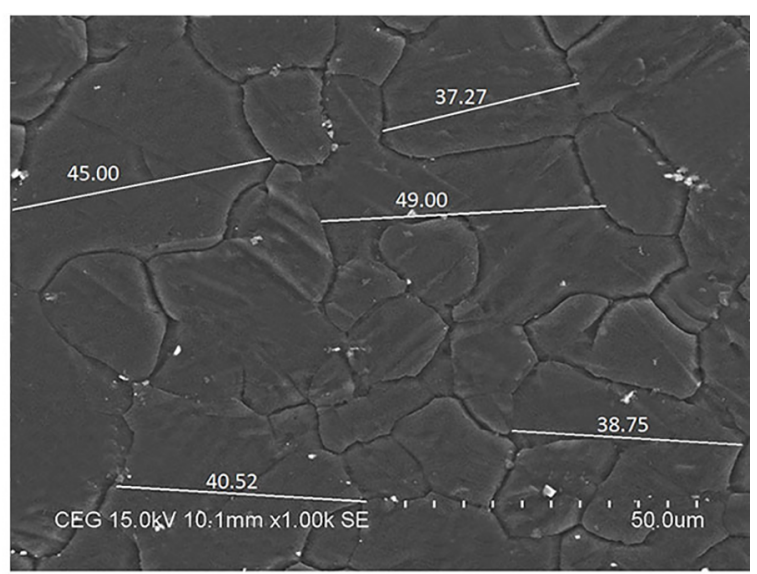

(b)

Figure 8. (a) Optical Micrographs image (b) SEM Image of base metal

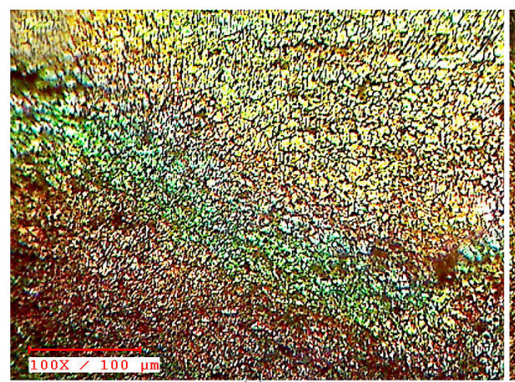

(a)

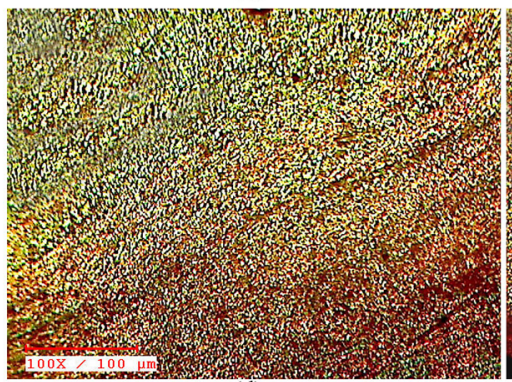

(d)

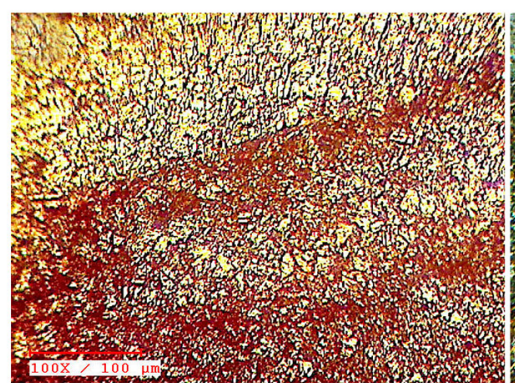

(g)

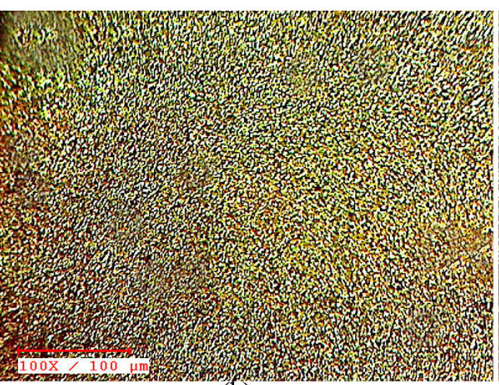

(b)

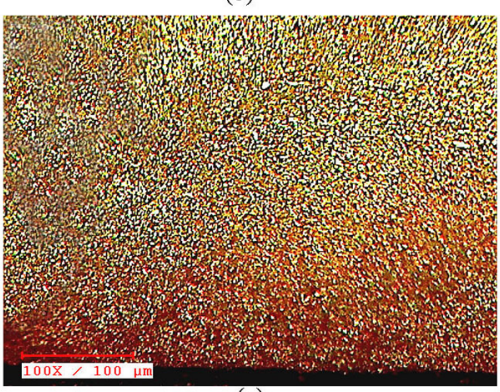

(e)

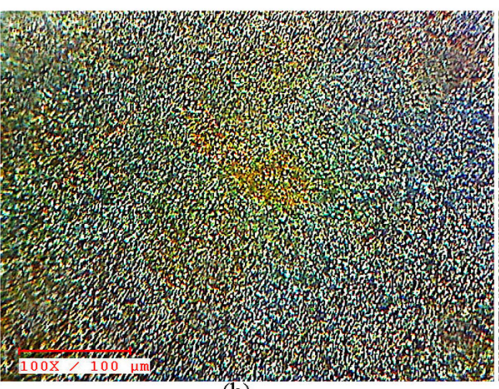

(h)

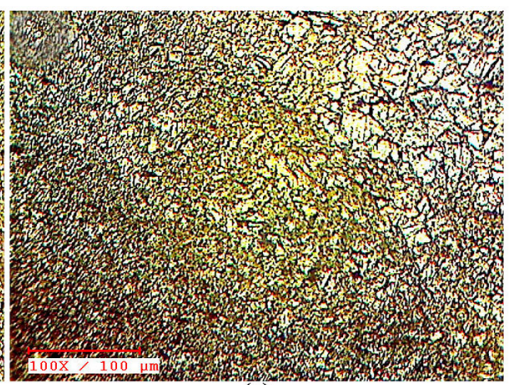

(c)

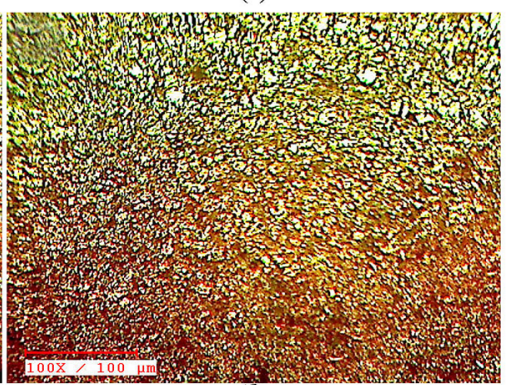

(t)

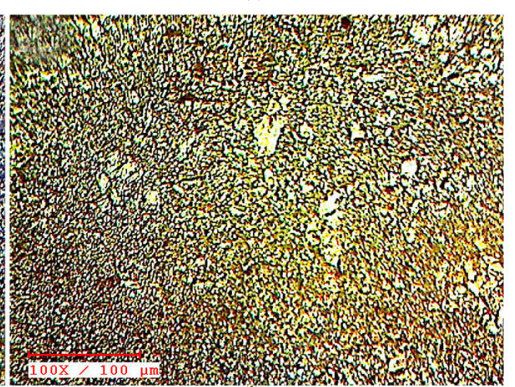

(i)

Figure 9. Optical micrographs of various regions of SFSP on Scroll Tool pin Profiles 
within the processed region arising as a result of severe and rapid deformation, while sound stir zones (SZ) were obtained by all the applied pin designs. The SZ consisting fine grains with an interface between stir and thermomechanical affected zones (TMAZ) were seen as free from any prominent defects. Grains in the (TMAZ) have been highly extruded and were seen with substantial elongation for all the considered workpiece. This is due to the heat and mechanical action. There is a small change due to the stirring process Figs. 8 (b, e and $\mathrm{h})^{33}$. When compared with SCL and SSCL, SSSQ tool pin profile resulted in clear microstructure. It containing very fine particles of primary and secondary phases with evident uniform dispersal. However, much finer grains were achieved for SSSQ pin due to optimum heat supply and stirring action. During processing, the heat affected zone did not undergo any plastic deformation, as it experienced only thermal cycles. The sample displayed similar grained microstructures as base metal Figs. 9(c and f). Figs. 9(a-i) indicate coarse grain and the microstructure observed for three different tool pin profiles at optimal processes parameter condition.

Results for grain size of the base alloy Fig 8(b) and dynamic re-crystallization of AZ31B produced by these tests are shown in Fig.(10). These prove that the base alloy had a nonhomogeneous microstructure with an average grain size of $41.30 \mu \mathrm{m}$. The SEM images indicate a microstructural change taking place in which, the coarse grains structure in the base alloy was modified into a substantial fine grain structure in the stir zone of the processed samples. These results could be attributed to a decrease in grain size and uniformity and change in the value of Mg17A112. Comprehensive elimination of the $\mathrm{Mg} 17 \mathrm{Al} 12$ phase arisen from the FSP process was reported by Venkateswarlu et al. ${ }^{34}$. The scrolled shoulder stepped pin profile produced a higher fine grain structure Fig. 10(c) when compared to the other tool pin profiles Figs. 10 (a- b). The average size of grains resulting from scrolled pin of SCL.SSCL and SSSQ were $8.48 \mu \mathrm{m}, 4.90 \mu \mathrm{m}$ and $1.99 \mu \mathrm{m}$, respectively. Reduction in the process temperature with cooling system and lowering the total time of the process resulted in more uniform and smaller grain size of microstructure. The same result was observed by Darras and Kishta ${ }^{30}$, in submerged friction stir process of AZ31. These ultra-fine grains are also proved by micro-hardness tests. The typical micro-hardness reading, hardness, consistent to the ultra-fine stir zone of the SFSP specimens are presented in Fig.7(b). The higher hardness value approximate $112 \mathrm{Hv}$, which is significantly higher than that of other pin profiles and received material.

\subsection{Fracture analysis}

The fracture surface of the base metal, SFSP processed samples using SCL, SSCL and SSSQ pin profiles are shown in Table 4. The base metal shows the existence of the different fracture modes like cleavage type fracture

Table 4. Fracture surface of tensile specimens using different tool pin profiles.

\begin{tabular}{|c|c|c|c|}
\hline Tool Pin & $\mathrm{HV}_{(0.5)}$ & Fracture zone & Fractured samples \\
\hline $\begin{array}{l}\mathscr{E} \\
\mathbb{E} \\
\mathscr{E}\end{array}$ & 72 & & \\
\hline$\circlearrowright$ & 89.23 & & \\
\hline$\underset{\sim}{\mathscr{S}}$ & 88.10 & & \\
\hline \multirow[t]{2}{*}{ 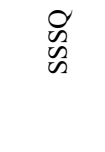 } & 112 & & \\
\hline & & $58 \mathrm{~mm} \times 15$ sE & \\
\hline
\end{tabular}




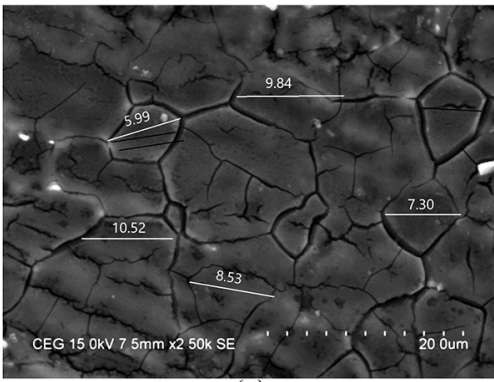

(a)

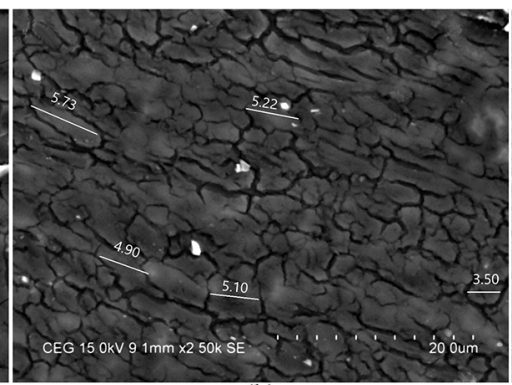

(b)

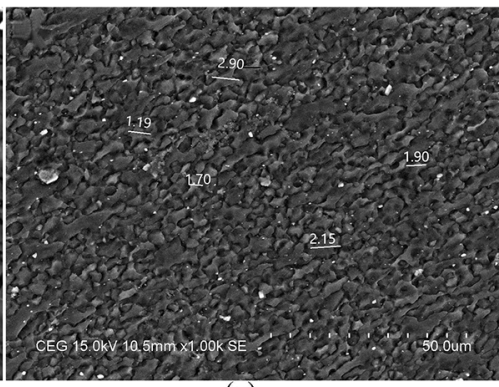

(c)

Figure 10. Effect of scroll tool pin profiles on SFSP zone SEM images (Rotational Speed: 1000 rpm) (a) Scrolled Cylindrical, (b) Scrolled Stepped Cylindrical, (c) Scrolled Stepped Square

mode exists and larger voids representing lower ductility. Except for the base metal, all the remaining samples were processed using SFSP that provided the ductile mode of fracture by micro void coalescence.

The fracture surface for the scrolled cylindrical and scrolled stepped cylindrical samples were also found to be more flat suggesting a little higher ductility, when it is compared to the base metal. On the other hand, large size dimples were formed on the sample produced using Scrolled Stepped Square pin profile (SSSQ) by revealing higher ductility ${ }^{19}$. The joints welded at higher heat input conditions resulted in more ductile fracture mode than that of the joints welded at lower heat input conditions. The fractured surface of the sample shows the shallow dimples, which leads the higher tensile strength and ductility.

\section{Conclusion}

Investigations on the role of submerged friction stir processing of AZ31B magnesium alloy have been carried out and the results obtained are summarized as follows.

1. Cylindrical, Stepped Cylindrical, and Stepped Square pin tool geometries are effectively relevant for producing defect free processed material.

2. Among the different pin profiles which are used, the ultra-fine grain size of $1.99 \mu \mathrm{m}$ is attained with SSSQ pin profile which was the least compared to the size of $8.48 \mu \mathrm{m}$ and $4.99 \mu \mathrm{m}$ was obtained with SCL and SSCL respectively. Hence, the maximum grain alteration attained was $1.99 \mu \mathrm{m}$ by SSSQ pin considering the grain size of $41 \mu \mathrm{m}$ for the received material before processing.

3. The microstructure evaluation obtained by SSSQ pin in SFSP with the tool rotational speed of 1000 $\mathrm{rpm}$ and traverse speed of $60 \mathrm{~mm} / \mathrm{min}$ resulted in tensile strength, elongation and micro-hardness of $245 \mathrm{MPa}, 23.46 \%$ and $112\left(\mathrm{HV}_{0.5}\right)$ due to its pulsation effect leading to a higher degree of plastic deformation, higher heat input and the effect of the shoulder geometry on the grain size of $\mathrm{NZ}$ in the processed material.
4. Cleavage type of fracture mode existed in the received base material and ductile fracture morphology for SCL and SSCL, whereas, a completely dimple like fracture mode to existed in SSSQ pin profile.

\section{Acknowledgements}

The authors gratefully acknowledge the Science \& Engineering Research Board, Department of Science and Technology (SERB-DST), New Delhi, India, for Central facility (Friction Stir Welding Machine) created through the project no.SR/S3/MERC/0092/2011, which was utilized for this research paper.

\section{Reference}

1. Patridge PG. The crystallography and deformation modes of hexagonal close-packed metals. Metallurgical Reviews. 2013:169-194.

2. Quan GZ, Zhang Z, Pan J, Xia Y. Modelling the Hot Flow Behaviors of AZ80 Alloy by BP-ANN and the Applications in Accuracy Improvement of computations. Materials Research. 2015;18(6):1331-1345.

3. Gong X, Gong W, Kang SB, Cho JH. Effect of Warm Rolling on Microstructure and Mechanical Properties of Twin-roll Casted ZK60 Alloy Sheets. Materials Research. 2015;18(2):360-364.

4. Givi MKB, Asadi P. Advances in Friction Stir Welding and Processing. Cambridge: Woodhead Publishing; 2014.

5. da Silva EP, Oliveira VB, Pereira VF, Maluf O, Buzolin RH, Pinto HC. Microstructure and Residual Stresses in a Friction Stir Welded Butt Joint of as-cast ZK60 Alloy Containing Rare Earths. Materials Research. 2017;20(3):775-779.

6. Hu HJ, Li YY, Gong XB, Zhai ZY, Wang H, Fan JZ, et al. Relationships between the process conditions and microstructures evolution for extrusion-shear of magnesium alloy. Russian Journal of Non-Ferrous Metals. 2015;56(4):455-460.

7. Blawert C, Hort N, Kainer KU. Automotive Applications of Magnesium and its alloys. Transactions of the Indian Institute of Metals. 2004;57(4):397-408.

8. Luo X, Fang D, Li Q, Chai Y. Microstructure and mechanical properties of An Mg-4.0Sm-1.0Ca alloy during thermomechanical treatment. Journal of Rare Earths. 2016;34(11):1134-1138. 
9. Zhao G, Xu S, Luan Y, Guan Y, Lun N, Ren X. Grain refinement mechanism analysis and experimental investigation of equal channel angular pressing for producing pure aluminum ultrafine grained materials. Material Science and Engineering: $A$. 2006;437(2):281-292.

10. Straumal BB, Sauvage X, Baretzky B, Mazilkin AA, Valiev RZ. Grain boundary films in Al-Zn alloys after high pressure torsion. Scripta Materialia. 2014;70:59-62.

11. Naeini MF, Shariat MH, Eizadjou M. On the chloride-induced pitting of ultra fine grains 5052 aluminum alloy produced by accumulative roll bonding process. Journal of Alloys and Compounds. 2011;509(14):4696-4700.

12. Woo W, Feng Z, Clausen B, David SA. In situ neutron diffraction analyses of temperature and stresses during friction stir processing of Mg-3Al-1Zn magnesium alloy. Materials Letters. 2017;196:284-287.

13. Barmouz M, Zall V, Pashazadeh H. Mechanical and Microstructural characterization of Hybrid Cu-SiC-Zn Composites Fabricated Via Friction Stir Processing. Materials Research. 2016;19(6):12921298.

14. Mishra RS, Ma ZY. Friction stir welding and processing. Materials Science and Engineering: R: Reports. 2005;50(12):1-78.

15. Ganesa Balamurugan K, Mahadevan K. Investigation on the changes effected by tool profile on mechanical and tribological properties of friction stir processed AZ31B magnesium alloy. Journal of Manufacturing Processes. 2013;15(4):659-665.

16. Wang Y, Huang Y, Meng X, Wan L, Feng J. Microstructural evolution and mechanical properties of $\mathrm{Mg}-\mathrm{Zn}-\mathrm{Y}-\mathrm{Zr}$ alloy during friction stir processing. Journal of Alloys and Compounds. 2017;696:875-883.

17. Nascimento F, Santos T, Vilaça P, Miranda RM, Quintino L. Microstructural modification and ductility enhancement of surfaces modified by FSP in aluminium alloys. Materials Science and Engineering: A. 2009;506(1-2):16-22.

18. Mao Y, Ke L, Liu F, Chen Y, Xing L. Effect of tool pin-tip profiles on material flow and mechanical properties of friction stir welding thick AA7075-T6 alloy joints. International Journal of Advanced Manufacturing Technology. 2017;88(1-4):949-960. DOI: $10.1007 / \mathrm{s} 00170-016-8882-\mathrm{z}$

19. Khodaverdizadeh H, Heidarzadeh A, Saeid T. Effect of tool pin profile on microstructure and mechanical properties of friction stir welded pure copper joints. Materials \& Design. 2013;45:265-270.

20. Heidarzadeh A, Saeid T, Khodaverdizadeh H, Mahmoudi A, Nazari E. Establishing a Mathematical Model to Predict the Tensile Strength of Friction Stir Welded Pure Copper Joints. Metallurgical and Materials Transactions B. 2013;44(1):175-183.

21. Heidarzadeh A, Barenji RV, Esmaily M, Ilkhichi AR. Tensile Properties of Friction Stir Welds of AA 7020 Aluminum Alloy. Transactions of the Indian Institute of Metals. 2015;68(5):757-767.
22. Chai F, Zhang D, Li YY, Zhang WW. High strain rate superplasticity of a fine-grained AZ91 magnesium alloy prepared by submerged friction stir processing. Materials Science and Engineering: $A$. 2013;568:40-48.

23. Chai F, Zhang D, Li YY. Microstructures and tensile properties of submerged friction stir processed AZ91 magnesium alloy. Journal of Magnesium and Alloys. 2015;3(3):203-209.

24. Rathinasuriyan C, Senthil Kumar VS. Experimental investigation of weld characteristics on submerged friction stir welded 6061-T6 aluminum alloy. Journal of Mechanical Science and Technology. 2017;31(8):3925-3933.

25. Hofmann DC, Vecchio KS. Submerged friction stir processing (SFSP): An improved method for creating ultra-fine-grained bulk materials. Materials Science and Engineering: A. 2005;402(12):234-241.

26. Pan F, Xu A, Deng D, Ye J, Jiang X, Tang A, et al. Effects of friction stir welding on microstructure and mechanical properties of magnesium alloy Mg-5Al-3Sn. Materials \& Design. 2016;110:266-274.

27. Santhanam SKV, Ramaiyan S, Rathinaraj L, Chandran R. Multi response optimization of submerged friction stir welding process parameters using grey relational analysis. In: ASME 2016 International Mechanical Engineering Congress and Exposition; 2016 Nov 11-17; Phoenix, AZ, USA. Paper no. IMECE2016- 65797. p. V002T02A075. DOI: 10.1115/IMECE2016-65797

28. Babu SR, Senthil Kumar VS, Karunamoorthy L, Madhusudhan Reddy G. Investigation on the effect of friction stir processing on the superplastic forming of AZ31B alloy. Materials \& Design. 2014;53:338-348.

29. Leal RM, Galvão I, Loureiro A, Rodrigues DM. Effect of friction stir processing parameters on the microstructural and electrical properties of copper. International Journal of Advanced Manufacturing Technology. 2015;80(9-12):1655-1663. DOI: 10.1007/s00170-015-7141-z

30. Darras B, Kishta E. Submerged friction stir processing of AZ31 Magnesium alloy. Materials \& Design. 2013;47:133-137.

31. Amirafshar A, Pouraliakbar H. Effect of tool pin design on the microstructural evolutions and tribological characteristics of friction stir processed structural steel. Measurement. 2015;68:111116.

32. Razal Rose A, Manisekar K, Balasubramanian V. Effect of axial force on microstructure and tensile properties of friction stir welded AZ61 A magnesium alloy. Transactions of Nonferrous Metals Society of China. 2011;21(5):974-984.

33. Asadi P, Besharati Givi MK, Faraji G. Producing ultrafinegrained AZ91 from As-cast AZ91 by FSP. Materials and Manufacturing Processes. 2010;25(11):1219-1226. DOI: $10.1080 / 10426911003636936$

34. Venkateswarlu G, Devaraju D, Davidson MJ, Kotiveerachari B, Tagore GRN. Effect of overlapping ratio on mechanical properties and formability of friction stir processed Mg AZ31B alloy. Materials \& Design. 2013;45:480-486. 